\title{
Intensiivistavate väljendite kujundist
}

\begin{abstract}
Anneli Baran
Teesid: Eesti kõnekäändude ja fraseologismide andmebaas sisaldab rohkesti väljendeid tähenduses 'üldse mitte', 'mitte kõige vähematki', 'mitte vähimalgi määral', 'mitte nii paljugi/vähegi' jmt. Oma koha on siin leidnud teiste seas rumaluse, laiskuse jmt inimlike pahede karikatuurne rõhutamine. Sellega seoses võib rääkida ka väljendusviisi intensiivistamisest. Kirjutises vaatlengi lähemalt intensiivistavaid väljendeid, milles keskne kujund on nn hüperboolselt kasutatud metonüümia.
\end{abstract}

Märksõnad: intensiivistav väljend, hüperbool, metonüümia, mõisteline valdkond, metonüümiline hierarhia.

\section{Intensiivistav väljend kui hüperbool}

Intensiivistavaid väljendeid võiks nimetada ka hüperboolseteks. Rahvaluuletekstides vägagi levinud kujundina on hüperbool liialdus suurendavas või vähendavas suunas objekti või mõne omaduse iseloomustamiseks või võrdlemi$\underline{\text { seks, }}$, defineerib eesti rahvaluule õpikus Eduard Laugaste (Laugaste 1977: 187). Sellised stereotüüpsed liialdavad ütlemised on keelteülesed, s.t kõigis keeltes sisalduvad universaalid, ning sageli tuuakse valvenäitena vormel olen sulle tuhat korda öelnud, et... Et liialdamine suurendavas/vähendavas mõistes on iseenesest intensiivistav (intensiivne tähenduses 'mõjus, tugev') tegevus, olen selle omaduse järgi nimetanud ka vastavad väljendid. Varasemas käsitluses olen eritlenud viit tüüpi intensiivistavaid fraase (Baran 2003), seekord võtan vaatluse alla neist kaks ja toon juurde ühe uue väljendirühma.

Eesti keele fraseologismide hulka kuuluvate intensiivistavate lausetarindite all pean struktuuri alusel silmas pikemaid, kas

- et-kõrvallauses sisalduvaid fraase, mis muudavad pealauses esitatud ( $n i i$ korrelaadiga) väite intensiivseks (nt nii laisk, et aja hoovad alla) 
või

- eitavaid intensiivfraase ehk ei... -ki/-gi-konstruktsioone (nt ei anna kaigastki pähe lüüa).

Teisena mainitud fraasid on esimestega tihedas seoses, sest nii et konstruktsioon on sageli juurdemõeldav, nt 'keegi on nii rumal $\sim$ laisk $\sim$ kitsi, et...isegi mitte...'. Tõenäoliselt ongi selline tarind tekkinud nii et konstruktsiooni lühenemisel või analoogia põhjal.

Kolmanda suure rühmana olen intensiivistavate väljendite hulka lugenud võrretega võrdlused, milles küll vormiliselt ei pruugi esineda negatsiooni, ent mille sisu on gradatsioonist tingituna hüperboolne: nt teab sellest niisama palju nagu kass lusikast.

Intensiivistavate väljendite puhul on enamasti tegemist lühenemise tulemusena järelejäänud et-kõrvallausega. Samas ongi olulisim kõrvallauses sisalduv, sest esiletõste rõhk langeb just sellele osale. Eesti keele grammatika alusel liigituvad sellised laused kas

- kvantumilauseteks, konkretiseerides pealauses väljendatud omaduse või seisundi määra, tegevuse või protsessi intensiivsust jm

või

- viisilauseks, kuna nii-korrelaadiga lauses võib et-kõrvallause osutada ka kvalitatiivsele aspektile - tegevuse või protsessi toimumise viisile.

Et aga need aspektid on tihti peaaegu eristamatud, loetakse nad piirjuhtumiteks (EKG 1993: 302).

Teataval määral sarnanevad intensiivistavad väljendid fraseoloogilistele võrdlustele, sest nende koosseisu kuuluv sidend et näib esinevat komparatiivses ehk võrdlevas funktsioonis. Sellest lähtuvalt on näiteks eesti fraseoloogia uurija Ingrid Sarv pidanud õigustatuks selle väljenditerühma käsitlemist koos võrdlustega (Sarv 1960: 34). Katre Õim leiab aga, et tavavõrdlusest erinevalt osutatakse nendes võrdlusvahendi/komparaatori poole peal hoopiski võrdlusalusele sündmusele või olukorrale, mitte objektile, ning võrdluslausega öeldakse, et võrreldaval objektil on omadust mingi sündmuse toimumiseks vajalikul/ebapiisaval määral (Õim 2003: 24). Teisisõnu: kui võrdlusega väljendatakse pelgalt omadust, siis intensiivistava väljendiga kujutatakse selle kvaliteedi taset. Ka on K. Õim osutanud asjaolule, et tavavõrdluse korral võrreldakse üldjuhul kahte erinevat situatsiooni, mistõttu võrdlustehe on metafoorne, intensiivistavates väljendites seevastu jäädakse ühe ja sama situatsiooni piiridesse; seega tuleks selliste väljendite kujundiga seoses rääkida metonüümilisusest (samas: 24). 


\section{Kahetine kujund - metonüümia vs hüperbool}

Intensiivistavad/hüperboolsed väljendid on ilmselgelt kujundliku keele tüüpilised esindajad, torgates silma suure ekspressiivsusega, sest eredad kujundid on liialdamise puhul vältimatud.

Samas tekitab metonüümilisus, mille puhul on olulisim kahe semantilise struktuuri - siht- ja allikala - vaheline külgnevussuhe (siin põhjuse ja tagajärje suhe), küsimuse kahe kujundi - metonüümia ja hüperbooli - vahekorrast. Kui metonüümilise kõrvutuse korral on tegemist puhtalt semantilise tasandiga - olgu see siis realistlik, tõelevastav/kindlaks tehtav/kontrollitav/tõestatav või kujundlik/kujutluslik külgnevussuhe, siis hüperbooliga kaasneb selgelt mingi nihestatus situatsiooni suhtes. Nimelt ei vasta öeldu tegelikkusele ehk pole realistlik, kuid erinevalt tavalisest kõnesituatsioonist - kus kehtib keeleliste väljendite tõelevastavuse nõue ${ }^{1}$ - seda aktseptitakse (stilistilistel, argumentatiivsetel vm põhjustel). Kurt Feyaerts, kes on vaadelnud metonüümiaproblemaatikat just saksakeelsete rumaluse-temaatikaga väljendite põhjal, eelistab - jättes küll kõrvale kujundi tõelevastavuse kriteeriumi ja keskendudes kahe semantilise struktuuri külgnevussuhtele - kasutada hüperboolsete väljendite puhul kasutada pigem terminit "hüperboolselt kasutatud metonüümiad" (hyperbolically used metonymies) (Feyaerts 1999: 323). Sel moel välistuks vajadus teha juttu kahte tüüpi metonüümiast (otsene/realistlik versus kujundlik/mitterealistlik), mille puhul muidu n-ö põrkuks korrektse osutamise reeglit rikkuva struktuuriga hüperbool väljendi semantilise - antud juhul metonüümilise struktuuriga.

Seega on taas kord tegemist kujundlikule keelekasutusele igiomase erijoonega, mis välistab kindlate piiridega juhud. Siinkohal on kohane tsiteerida Arvo Krikmanni, kes on osutanud, et troobid on tegelikult semantiliselt komplekssed nähtused: “Troobid ei ole ega saagi sellistena olla üksteisest välistuvad, vaid asuvad mõisteliselt vahel soo- ja liigisuhetes (nagu metonüümia ja sünekdohh), vahel omavad mõistelist ühisosa (nt paradoks ja oksüümoron peavad kätkema mingit teravat sisulist vastuolu, absurdi), vahel on troopide vahel kokkupuute- või üleminekualasid, vahel esindab üks teise keelelist vormi (nt. asju mõneti lihtsustades võiks öelda, et võrdlus esindab metafoori süntaktilist vormi) jne. Fraseoloogias ja paröömikas kohtab haruharva nii lihtsa semantilise struktuuriga kujundeid, et neid saaks taandada teatud üheleainsale kindlale troobiliigile." (http://www.folklore.ee/ kriku/RETSEM/). 


\section{Liialdamine ja hinnangulisus}

Hüperbool kujundina on otseses seoses huumoriga, sest üldjuhul kaasneb paisutamisega naeruvääristamine. Selliseid liialdavaid väljendeid on võimalik käsitleda ka vähem või rohkem pilkamisi öeldud solvanguitena mis koosnevad kahest poolest: ühte lausepoolde on kätketud isiku mingi omadus, mis on negatiivse tähisega (negatiivselt väärtustatud), teisega illustreeritakse või põhjendatakse seda hinnangut/otsustust. Keskne tüüp esindab konstruktsiooni ' $\mathrm{X}$ on nii Y, et Z' (Brône \& Feyaerts 2003: 24jj). Sellistele metonüümilistele väljenditele omane tugev ekspressiivsus on saavutatud tänu tõsiasjale, et inimesed on teistesse negatiivset suhtumist väljendades äärmiselt loomingulised. Seda enam, kui kõnelejat ei kammitse vajadus valida tavakommunikatsiooni reeglitele kohaseimat väljendusviisi.

Väljenduslaadi mõjususest rääkides tõstatub veel üks aspekt. Et alljärgnevas käsitlemisele tuleva temaatilise valdkonna puhul on keskne koht liialdaval, tugevalt grotesksel kujutuslaadil ${ }^{2}$, millele on omane nihestatus hästi teadaoleva situatsiooni suhtes, võiks järeldada, et tõenäoliselt puudub liialdamist sisaldavate väljendite mõtestamisel vajadus konteksti-poolse toetuse järele. Rachel Giora esitatud salientsusteooria (silmatorkavuse teooria) kohaselt on mõistmisel tähtsaim - ühtlasi kõige hõlpsamini kättesaadavam ja esimesena aktiviseeritav - sõna või väljendi silmatorkav tähendus ehk tähendus, millel on koht mentaalses leksikonis (Giora 2003: 81). Tuttava väljendi puhul sisalduvad seal nii otsene kui ka ülekantud tähendus ja mõlemad aktiviseeritakse hoolimata kontekstist. Küsimus, kui tuttava-tuntuna on käsitletav tegelikkusega - küll äraspidi - suhestuv hüperbool, jääb esialgu vastavate uuringute puudumisel vastuseta. Samas kui lähtuda sellest, et selliste väljendite näol on ühtlasi tegemist fraseologismidega, mille tuvastamine ja mõtestamine peaks eeldatavasti toimuma automaatselt, võiks kehtida kontekstisõltumatus.

Eesti kõnekäändude ja fraseologismide baasi põhjal analüüsin järgnevalt väljendeid, mille temaatiline/kontseptuaalne/mõisteline valdkond on intellektuaalne võimekus. Väljenditele vastav parafraas on 'rumal, tobe, peast segi, põikpäine olema', 'ebapiisavaid teadmisi omama' - seega on sisuks pigem intelligentsuse puudumise hüperboolne rõhutamine, s.o liialdamine vähendavas suunas. Negatiivse temaatikaga väljendite rohkus fraseoloogias üldse osutab Natalia Filatkina sõnul keelelisele asümmeetriale, mille kohaselt välditakse negatiivse ja taunitava nimetamist otse ja tehakse seda pigem kujundlikku keele, sh fraseoloogia vahendusel (Filatkina 2005: 300). Ka eri keelte fraseoloogia alal tehtud uurimused näitavad, et selle temaatikaga väljenditele/mõistevaldkonnale on omane kõrge mentaalne esindatus. ${ }^{3}$ 


\section{Metonüümiline hierarhia}

Kurt Feyaerts eelistab analüüsida metonüümiat kui mõistelist mehhanismi (conceptual mechanism), selliselt on võimalik sarnaselt metafoorsetele hierarhiatele eritleda ka metonüümilisi hierarhiaid. Mõistelist metonüümiat saab Feyaertsi arvates kirjeldada samamoodi erinevatel üldistustasanditel (Feyaerts 1999: 323jj), ning ka antud juhul saab rumaluse kui seisundi võtta kokku skemaatilise mudeli alla, milles silmatorkav omadus tähistab vähemsilmatorkavat, sest teadupärast tajutakse füüsilisi ja sotsiaalseid omadusi tunduvalt hõlpsamalt kui abstraktseid mentaalseid omadusi. Või tsiteerides Ronald W. Langackeri: Metonüümia näol on tegemist esileküündiva viitepunktiga, mis osutab sihtalale maksimaalse täpsusega minimaalsete kognitiivsete pingutustega (Langacker 1993: 30). Samuti esinevad mõisteliste metonüümiate puhul erinevate kõrgemate skemaatiliste struktuuride (kontseptsioonide) kattumised ning kõrgema (skemaatilisema) tasandi metonüümiad kalduvad olema universaalsemad ehk puhtkognitiivse loomusega, seevastu madalama tasandi metonüümiad on kultuuriliselt rohkem kitsendatud/sõltuvad. Järgnevas käsitlengi lähemalt eestikeelseid intensiivistavaid rumaluse-väljendeid, võttes aluseks Feyaertsi metonüümiliste hierarhiate skeemi (Feyaerts 1999). Seejuures tuleb aga silmas pidada, et antud skeem on üldistus avarama keelematerjali põhjal kui siinkohal käsitlemist leidvad intensiivistavad väljendid.

- 'KESISED VAIMSED VÕI PRAKTILISED VÕIMED'

Selle rühma väljendite parafraasiks on 'ei oska ei tea isegi mitte...', tähenduses 'isegi mitte kõige elementaarsemat', st täielik võimetus/oskamatus tulla toime elementaarsete tegevustega:

nii rumal, et ei tea pooli pudrunõusid;

sa tii-äi puoli sepävasaritki;

nõnda rumal, et ei märka teretadagi (vrd sigagi röhib, kui vasta tuleb;

siga külatänavas tuleb vastu, röhib koa, aga inimene ei mõista teretada); ei mõista musta tähtegi (vrd ta ei tunne mitte, mis must valge peal on); ninda loll, ei muista kolme lugeda ei mõista enam viit lugeda;

ei oska mitte varsa ja vasika vahelgi vahet teha;

ei tiie, mes lind vares on terve eluaja karjas käind ja ei tunne veel varest

karjus ei tea, kas lehmal sarve pääs om;

ei oska sealauda pulkagi teha ei mõistnud vankripulka kah ette teha ei mõista varese persepulka teha;

Siia rühma paigutuvad ka eitavad sõnapaarid, mis muudavad väljendi intensiivseks n-ö topeldamise teel: 
sais nigu puutomp, is lausu musta is valget;

ta om nii seräne tuhakott, et ei tiiä maast ei ilmast midagi;

mõni laps on niske molo, ei tiä üüd ei päeväa.

Ka väljendid 'ei tea muud kui...', st 'teab ainult väga elementaarseid ja primitiivseid asju', esindavad KESISTE VAIMSETE VÕIMETE kontseptsiooni. Väljend koosneb komparatiivsidesõnast kui ja sellega seostuvast pronoomenist muu (tähenduses 'ei tea mitte rohkem kui...'). Siin rühmas päädib liialdus enamasti groteskiga (konn kui lind ja lepp kui lill):

ei tea muud kui taevas ja maailm (on) ja tuul käib mööda nina;

ei tiia muud kui kulp ja tsiapang;

pea ei jaga muud kui tatti;

ei tea muud lindu kui konna;

ei tunne muud lille kui leppa ja muud lindu kui konna;

muud lindo ta ei tunnõ kui sitiket ja hainaritsket;

muud paremad laululindu ei tunne ma kui sitasitikat ja konna-konn see

krooksub krooks, krooks, krooks, sitik ikka urr, urr, urr.

- 'KASIN MÕISTUS AJAB KIMBATUSSE'

Siia rühma paigutasin väljendid, milles tögatakse kedagi, kes on sedavõrd vaimselt puudulik, et see toob endaga n-ö paratamatu (pigem küll kummastava) tagajärje, mis mõjub pigem omalaadse (füüsilise) karistusena:

tuu om nii rummal, et toolõ aja hüdsekot't pähä‘(vrd justkui süekott pähä aetud 'pururumal');

nii loll, et isegi päike ei paista peale;

nii loll, et ei haise $k$ a enam;

nii loll, et ei libise ka enam.

- ' 'HÄLBELINE KÄITUMine (= KÕNELEMINE) KUI PÕHJUS'

Kellegi käitumisviis või jutt on sedavõrd (äärmuslikult) naeruväärne, et isegi loomad ja siit ilmast lahkunud inimesed reageerivad sellele põlastusega:

seda naeravad külaseadki /külakoeradki naeravad ajab nii hulle jutte,

et kanadki naeravad seda naeravad kõik ilma hammasteta sead ka; see jutt ajab surnud ka naerma sa ajad oma jutuga haigedki naerma; seda rumalust nähes pöörab surnu ka hauas end ringi.

- 'Olematu mõistus'

Väljendite parafraas kõlab 'kellelgi pole aru peas mitte niigi vähe kui...', sisuliselt aga 'puudub vähimalgi määral', st jutt ei ole enam aru nappimisest, vaid lausa puudumisest. Ingrid Sarvel on sellised väljendid omaette võrdluste ala- 
liik nimetusega väärt-võrdlus (Sarv 1960: 38). Liialdus põhineb vähendusel, s.t 'isegi mitte nii vähe kui...':

ei ole ninatubaka väärt aru peas (vrd kui nenätubakka 'vähe');

ei ole mitte juuksekarva väärt aru pääs;

ei ole mõistust nahanõgla väärtki;

mõistust ei ole kopka iestki; sul ei ole poole kopika eest aru peas (vrd ei ole punast kopikatki $\sim$ krossigi).

Siia rühma paigutuvad sarnaselt eelnevatele väljenditele ka väljendid parafraasiga 'kellelgi pole aru/mõistust mitte vähimalgi määral', st 'üldse mitte'. Leksikaalselt koosseisult moodustavad selliste väljendite tuuma kontekstisünonüümidena esinevad rõhutatult eitavad kvantorsõnad (vt EKG 1993) raasugi ivagi palagi juppigi põrmugi tuhkagi $\sim$ maikugi $\sim$ haisugi $\sim \tilde{h} k u g i$ :

aru pole raasugi; ei ole aru mitte ivaki pähän;

ei ole aru / meele / oiu tuhkagi peas;

põle aru põrmugi; ei sul ole mõistuse põrmugi pias;

ei ole arupalakest rei ole arukuse juppi pää sehen;

põle aru / meele / mälu haisugi piäs;

pole enam aru maikugi pääs;

põle mõistust mette jumala õhkugi peas.

Kolm järgmist näiterühma sisaldavad võrdlemist ja on tugevalt absurdimaigulised, sest inimese vaimset võimekust võrreldakse looma omaga - taustaks kontseptuaalne metafoor INIMENE ON LOOM, täpsemalt RUMAL INIMENE ON LOOM. Et selline võrdlus välistaks inimesega lahutamatult seotud sotsiaalse mõõtme, võiks selliseid väljendeid käsitleda ka sotsiaalse võimetuse sedastustena.

Esimese allrühma parafraas ütleb, et 'kellelgi pole aru isegi mitte nii palju kui / veel vähem kui mõnel teataval koduloomal (kanal, kitsel, lambal, vasikal, varsal)':

ei ole ahtra kitse arugi pääs;

ei ôle lamma vasta aru;

pole vasika arugi;

sul põle mitte õiged varsa arugi;

pole mõistust mette niigist pailukest kut kana jala peel liha sul ei ole nii palju aru haisugi pääs kui kana jala pääl liha.

Teise, isegi arvukama näitestikuga esindatud rühma parafraas: 'ei tea rohkem/ei ole targem kui, teab sellest sama palju kui... \{siga, lammas, hunt, kana, kass\}'. Sellised väljendid põhinevad olemuslikult samastaval võrdlemisel, kuid samastavateks on inimene ja loom. Viimaselt eeldatakse neile mitteomaseid (inimlikke) teadmisi, mistõttu tekib taas tugevalt absurdile viitav väljend: 
ta oo na rumal, et ei tia kellegist kedagi nagu siga pühabäst päävast; teab

niisama pallu kui lammas laubaõhtast ja põrsas pühapäevasest päevast; ei tea mitte sest rohkem kui siga pühapäisest päevast ehk hunt hapukapsaleemest;

ei tea sest nii palju kui kana kirjast;

ei tema tiï̈ tost rohkemp kui tsiga hõbelusikast teab sellest niisama palju nagu kass lusikast.

Kolmanda allrühma moodustavad võrdlused, mis on pigem kõrvutavad/astendavad, teisisõnu gradatsioonilised, kui sarnastavad/samastavad: 'keegi on rumalam/ mitte targem kui ... \{vasikas-lehm, põrsas-siga\}'

Võrreldes mingi traditsiooniliselt rumalaks peetava loomaga on tögamise sihtmärgiks sattunud inimene vaimselt veelgi madalama võimekusega:

rumalam kui köstri lehma vasikas/köstri kirju lehm < rumal kui köstri vasikas;

rumalam kui rublane põrsas < rumal kui rublane põrsas;

veel lollim kui siga; siga on ka targem (vrd kes minust lollem on, see on

siga ja sea üle on nuga).

Samas ei pruugi võrdlusvahend pärineda sugugi üksnes loomariigist, vaid selleks võib olla ka midagi majapidamisriistade hulgast; tulemuseks groteskne võrdluspilt elusa ja eluta objekti kõrvutamisest: ei ole targem kui luuavars nurgas < rumal/tark nagu luuavars.

Võrrelda võidakse ka sel moel, et vastandatakse kaks eri kohta 'kuskil on midagi (antud juhul tarkust) enam kui mujal':

minu perses on rohkem tarkust kui sinu peas;

minu keldres on rohkem tarkust kui sinu pööningul.

Teise väljendi puhul on tegu somaatilise võrdlemisest ehitisega sündinud asendamisega (pea kui pööning); samal metafoorsel assotsiatsioonil põhinevaid väljendeid leidub rumaluse-temaatikaga fraseologismide seas teisigi: tuul käib pööningult läbi; pööning on sassis.

- 'HäLBELINE VANUS'

Viimase suure rühmana tooksin välja väljendid, milles lõikuvad kaks mõistevälja: ühtelt poolt on markeriks vanus, teisalt n-ö hälbeline välimus. Silmatorkavalt sarkastilise konnotatsiooniga väljendid on üldjuhul pilked vanemate inimeste jutule vahele segama kippuvate noorukite aadressil. Väljendite koosseisu kuulub partikkel 'alles', mis esineb ajalises tähenduses ning täidab intensiivistavat funktsiooni. Liialdamisega vähendavas suunas 'keegi on veel nii noor, et...' seostatakse omavahel vähene taip ja vanus, tulemiks noorusest tingitud rumalus: 
suu alles piimane; alles tissiase moka sehes; endal alles kõrvatagused märjad;

alles piimahambad suus;

alles nina tatine; püheb alles käisega nina; nenaalust ei õska viel pühkida;

lapse sitt alles perses;

särgihänd alles niiske

enesel alles perse maa külges kinni, toll pea ja persse vahet;

alles munakoored perses alles munakarv peal alles nuur kui munakoor; alles talle reied nina all varsa jalad nina all;

nokk alles kollane (vrd liitsõna kollanokk).

Mõjususe suurendamiseks harrastatakse kumuleerivat väljenduslaadi:

enesel alles talle reied nina all ja munakoored persses;

sul om kuklaperä viil hämm ja imäpiim om huulekolgan, kas sa täis ei ole eih, sa olõt viil poiskene;

tuo mõni naasevõtja viel: nõna nõline, perse pasane.

\section{Kokkuvõtteks}

Antud analüüsi eesmärk oli selgitada ühe kindla temaatikaga väljendite näitel nende kujundilist hübriidsust. Intensiivistavates väljendites põrkuvad metonüümia ja hüperbool. Kurt Feyaertsi termin hüperboolselt kasutatud metonüümiad annab ühe võimaluse metonüümia ja hüperbooli vahekorra selgitamiseks. Samuti on mõttekas analüüsida fraseologismide kujundlikkust, määratledes metonüümiat kui kontseptuaalset mehhanismi ja kasutades metonüümiliste ülekannete selgitamiseks hierarhilist mudelit.

\section{Kommentaarid}

1 Tegemist on ühega Paul Grice'i neljast maksiimist, nimelt kvaliteedi maksiimiga, mille rikkumine ei taga edukat infovahetust (Grice 1991: 22).

${ }^{2}$ Sama temaatikaga fraseologisme on saksakeelse empiirika najal süvitsi käsitletud kahes doktoritöös: Kurt Feyaertsi Die Bedeutung der Metonymie als konzeptuellen Strukturprinzips. Eine kognitiv-semantische Analyse deutscher Dummheitsausdrücke (1997) ja Natalia Filatkina monograafias Phraseologie des Letzebuergeschen: Empirische Untersuchungen zu strukturellen, sematisch-pragmatischen und bildlichen Aspekten (2005).

3 Siinkohal osutan Arvo Krikmanni monograafiale "Sai hea obaduse vastu obadust": Löömist ja peksmist märkivad väljendid eesti keeles (2004), kus analüüsides peksuteemalist fraseoloogiat eritleb autor ka konsekutiivhüperboole, tuues esile neile iseloomuliku grotesksuse. 


\section{Kirjandus}

Baran, Anneli 2003. Fraseoloogilise materjali analüüsivõimalustest. Uurimusi folkloori lühivormidest. Reetor 1. Tartu: Eesti Kirjandusmuuseum, folkloristika osakond, Eesti Kultuuriloo ja Folkloristika Keskus, lk 9-51.

Brône, Geert \& Feyaerts, Kurt 2003. The cognitive linguistics of incongruity resolution: Marked reference-point structures in humor. [8th International Cognitive Linguistics Conference: July 20-25, 2003, University of La Rioja, Spain. Theme session: CognitiveLinguistic Approaches to Humour] (http://wwwling.arts.kuleuven.ac.be/iclc/Papers/ BroneFeyaerts.pdf - 13. november 2007.)

EKG 1993 = Mati Erelt, Reet Kasik, Helle Metslang, Henno Rajandi, Kristiina Ross, Henn Saari, Kaja Tael, Silvi Vare. Eesti keele grammatika II. Süntaks. Lisa: Kiri. Toim Mati Erelt, Tiiu Erelt, Henn Saari, Ülle Viks. Tallinn: Eesti Teaduste Akadeemia Keele ja Kirjanduse Instituut.

Feyaerts, Kurt 1997. Die Bedeutung der Metonymie als konzeptuellen Strukturprinzips. Eine kognitiv-semantische Analyse deutscher Dummheitsausdrücke. Katholieke Universitet Leuven, PHD thesis.

Feyaerts, Kurt 1999. Metonymic Hierarchies. The Conceptualization of Stupidity in German Idiomatic Expressions. Metonymy in Language and Thought. Panther, KlausUwe; Radden, Günter (toim), 309-332.

Filatkina, Natalia 2005. Phraseologie des Letzebuergeschen: Empirische Untersuchungen zu strukturellen, sematisch-pragmatischen und bildlichen Aspekte. Dissertation. Germanistische Bibliothek Bd. 22. Universitätsverlag Winter.

Giora, Rachel 2003. On our mind: salience, context, and figurative language. Oxford: Oxford University Press.

Grice, Paul 1991. Studies in the Way of Words. Cambridge (Mass.) [etc]: Harvard University Press.

Krikmann, Arvo 2004. "Sai hea obaduse vastu obadust”: Löömist ja peksmist märkivad väljendid eesti keeles. Reetor 3. Tartu: Eesti Kirjandusmuuseum, folkloristika osakond, Eesti Kultuuriloo ja Folkloristika Keskus.

Krikmann,Arvo. Ütluste semantikast. (http://www.folklore.ee/ kriku/RETSEM/ - 1. juuli 2007).

Langacker, Ronald W. 1993. Reference-point constructions. Cognitive Linguistics 4: 138.

Laugaste, Eduard 1977. Eesti rahvaluule. Tallinn: Valgus.

Sarv, Ingrid 1960. Rahvapärane võrdlus kui kõnekäänu eriliik. Tartu Riikliku Ülikooli toimetised 94. Tartu: Tartu Riiklik Ülikool.

Õim, Katre 2003. Võrdluste struktuurist ja kujundisemantikast. Reetor 2. Tartu: Eesti Kirjandusmuuseumi folkloristika osakond, Eesti Kultuuriloo ja Folkloristika Keskus. 


\title{
Summary
}

\section{On the Imagery of Intensive Phrases}

\author{
Anneli Baran
}

Key words: intensive phrases, hyperbole, metonymy, conceptualisation, metonymic hierarchies

The database of Estonian phrases contains numerous hyperbolic phrases such as üldse mitte 'not at all', mitte kõige vähimatki 'not in the least', mitte vähimalgi mä̈̈ral 'not one bit'. These phrases are mostly expressions of negation, and could be more specifically referred to as negation intensive phrases. In these phrases, hyperbole is mostly concerned with caricaturelike exaggeration of ignorance, indolence, or any other human vice. Such exaggeration may often lead to the grotesque or absurd. This paper investigates the use of hyperbole as a stylistic device in more detail. 